\title{
doispontos:
}

\section{Vida artista, vida livre}

\author{
Guilherme Castelo Branco \\ Laboratório de Filosofia Contemporânea, Universidade Federal do Rio de Janeiro, Rio de Janeiro, Brasil \\ guilhebranco@gmail.com
}

Resumo: O artigo, que trabalha com os textos originais de Foucault, apresenta os vínculos entre os conceitos de 'vida artista', 'estética da existência' e de 'resistência ao poder'. Sua hipótese é a de que existe estreito vínculo entre estética, política e liberdade na fase madura(1978-1984) do filósofo francês.

Palavras-Chave: vida artista; estética da existência; resistência ao poder; Foucault, M.; liberdade; atualidade.

\section{Artistic life, free life}

Abstract: Dealing with Foucault's original texts, this article demonstrates the relations between the concepts of 'artistic life','aesthetics of existence' and 'resistance to power', which brings to the hypothesis of a relationship between aesthetics, politics and freedom in French philosopher's maturity works (1978-1984).

Key-words: artistic life; aesthetics of existence; resistance to power; Foucault, M; freedom; actuality.

Um dos temas mais importantes dos últimos tempos, na filosofia francesa, gira em torno das tecnologias ou artes da existência. O problema da beleza que pode ser criada pelos sujeitos, em suas vidas, é tema recorrente. Os artistas, como sempre, foram os que levantaram a problematização sobre como se construir uma vida bela, com grande antecipação, no século XIX. Oscar Wilde, Arthur Rimbaud, Charles Baudelaire, são alguns artistas que trouxeram o tema para a Modernidade. Somente muito depois é que o assunto entrou na pauta dos intelectuais e pensadores. Leitores sensíveis ao mundo da arte, assim como teóricos em estética, e, acima de tudo, todos aqueles tocados pela arte de viver, compreendem a importância do vínculo entre beleza e vida. Trata-se de uma questão que inquieta a muitos, pois é um tema possível para toda pessoa, mulher ou homem, capaz de exercício ético e de uma verdadeira construção subjetiva.

Vejamos uma das passagens onde tal inquietação está claramente indicada, num texto de Michel Foucault: "o que me surpreende é que em nossa sociedade a arte esteja relacionada apenas aos objetos e nunca aos indivíduos e à vida; e, também, que a arte esteja num domínio especializado, o dos experts que são artistas. Mas a vida de todo indivíduo não é uma obra de arte? Por que uma mesa ou uma casa são objetos de arte, mas não as nossas vidas?”(FOUCAULT, 1994, vol. IV, pág. 617). Não se trata da arte como posse do objetos considerados belos, mas da arte como vida, enquanto uma estética da existência.

A estética da existência, deste modo, pode ser definida como a resposta teórico-prática à pergunta sobre a beleza a se dar à vida, à própria existência, em especial se levamos em consideração que ela tem como cenário a atualidade e formas de vida recentes ${ }^{1}$. O mundo que nos cerca não é, exatamente, um tempo que incentiva formas de vida rebeldes e indóceis; pelo contrário, incentiva formas de vida conformadas e acomodadas. 
O ponto de partida a respeito da estética da estética tem origem na antiguidade, mas não pode ser utilizada tal qual no mundo contemporâneo: "dentre as invenções culturais da humanidade, há todo um tesouro de procedimentos, técnicas, idéias, mecanismos, que não podem ser, verdadeiramente, reativadas, mas que podem ajudar a constituir uma espécie de ponto de vista que pode ser útil para analisar e transformar o que se passa conosco na atualidade. \{\} Nós não temos que escolher entre nosso mundo e o mundo grego. Mas, uma vez que podemos observar que alguns dos grandes princípios morais de nossa moral foram vinculados, num determinado momento, a uma estética da existência, creio que este tipo de análise pode ser útil" (FOUCAULT, 1994, vol. IV, 616/617). O passado nada mais pode ser que um incentivo, à distância, do que é possível no presente.

Por outro lado, temos que deixar de pensar que a estética da existência limita-se a ser um aspecto do cuidado de si, que propõe a cada um de nós cuidar de seu mundo particular e de sua vida pessoal de forma moralista e encerrada em si mesma. A estética da existência comporta arestas, é produto de conflitos, se faz por contrapontos e pequenos combates e superação de desafios e, restrições, constrangimentos. A tal ponto que o filósofo francês afirma, não sem certo tom de provocação, no que se refere à sexualidade, por exemplo, que " de certo modo, viu-se a mesma coisa no século $\mathrm{XX}$, quando as pessoas, para terem uma vida mais bela e exuberante, procuraram se desembaraçar dos constrangimentos sexuais que lhes eram impostos pela sociedade. Na Grécia, Gide seria tido como um filósofo austero."(Foucault, 1994, vol. IV, pág. 616). Foucault, decididamente toma partido pela versão mais corrosiva e libertária do 'cuidado de si', pela qual um indivíduo (como Gide) se fabrica e resiste às práticas hegemônicas de poder, a partir de uma criteriosa intuição ou reflexão sobre os desafios abertos pelo tempo presente, entrando sempre em luta com os poderes hegemônicos, que sempre nos fornece formas de vida, modos de pensar e benefícios pela obediência e bom comportamento.

Praticar a vida artista é participar das lutas que visam à defesa da liberdade. O campo desses afrontamentos e resistências ao poder são as lutas contra a dominação(étnicas, sociais, religiosas), as lutas contra as formas de exploração(que separam o indivíduo do que ele produz), e, finalmente, as lutas que levantam a questão do estatuto do indivíduo. No rol das lutas em torno do estatuto do indivíduo estão as lutas contra o assujeitamento ${ }^{2}$, assim como as diversas lutas contra as diversas formas de submissão da subjetividade. Este último campo de resistência tem relevância, devido às muitas possibilidades de êxito, em função da multiplicidade de formas possíveis e de estratégias de ação que pode assumir. As lutas que discutem a questão do estatuto do indivíduo são bem mais radicais e criativas, do ponto de vista estratégico, que as outras formas de luta.

As lutas em torno do estatuto do indivíduo têm dois objetivos interdependentes: primeiro ponto, "afirmam o direito à diferença e apóiam tudo o que pode tornar os indivíduos verdadeiramente individuais. Segundo ponto, são "contrárias a tudo o que pode isolar o indivíduo, separá-lo dos outros, cindir a vida comunitária, constranger o indivíduo a dobrar-se sobre si e amarrá-lo à sua própria identidade”.(FOUCAULT, 1994, vol. IV, pág. 226/227) Toda luta pela autonomia consiste num processo iniciado na subjetividade, mas que não termina na esfera subjetiva. A luta pela autonomia do indivíduo não o conduz, em nenhuma hipótese, ao individualismo, ou seja, não o leva a uma forma de vida voltada para si e para seu mundo próximo, íntimo e familiar( no sentido da moralidade burguesa). O processo de singularização somente tem sentido quando culmina na superação do individualismo mediante uma nova aliança do indivíduo com novas formas de vida e com novos vínculos comunitários. Não devemos considerar que o indivíduo, com seu mundo 'familiar' e meu 'meio vital', seja o vetor principal das resistências ao poder. Pois a resistência iniciada na subjetividade prolonga-se mundo social, e é tarefa constante criar e recriar novas experiências, tanto pessoais quanto comunitárias. 
A recusa das formas de subjetividade que nos foram impostas converte-se, assim, numa questão política de real densidade: temos que procurar elaborar formas de vida livres e autônomas dentro de sistemas sócio-políticos que trabalham incessantemente para submeter as pessoas a práticas divisórias, disciplinares, individualizantes, normalizadoras, com o auxílio de técnicas e de conhecimentos científicos, e com o apoio de um conjunto de técnicas de controle

A estética da existência não poderia ser um modo de vida marcado pela arte e numa vocação subjetiva e individual, como se fosse resultado de um talento e genialidade do qual o artista é portador iluminado, como se a arte fosse vocação pessoal de certos indivíduos raros e especiais.

Ora, educamos a sensibilidade, podemos cuidar de nós mesmos e dos demais quando recebemos uma educação que ensina e sensibilidade e a construção subjetiva, num processo que nunca tem fim. Quem se aventura nesta senda realiza uma vida plena de sentido. A caminhada ao longo da existência é que dá o valor do trabalho de produção da estética da existência e da vida plena. A vida plena não está na juventude, na maturidade nem na velhice, mas na totalidade de uma vida inquieta pela sua beleza e pela plenitude. É ao longo do processo de vida que se revela o cuidado com a educação, de si próprio e dos outros, que nunca cessa nem deve cessar.

A arte-educação, neste particular, é um importante instrumento de iniciação e aprofundamento na árdua tarefa de sensibilização para a arte e para o sentido das coisas. Seu trabalho é crucial, pois dedica-se a muitas pessoas, de todas as faixas etárias, e podemos aprender que trata-se de um processo cheio de barreiras a serem ultrapassadas ${ }^{3}$.

A atitude pela qual tornamo-nos artífices da beleza de nossa própria vida, leva a um estilo de vida de alcance comunitário, e consiste num modo de vida "artista", realizável por todo aquele que seja capaz de questionamento ético e que seja realizador de uma atitude de modernidade. Segundo Foucault, "o prazer por si pode perfeitamente assumir uma forma cultural, como o prazer pela música. E deve-se compreender que trata-se, nesse caso, de alguma coisa muito diferente do que considera-se interesse ou egoísmo. Seria interessante verificar como, no século XVIII e XIX, toda uma moral do "interesse" foi proposta e inculcada na classe burguesa - por oposição, sem dúvida a todas as artes de si mesmo que poder-se-iam encontrar nos meios artístico-críticos; a vida "artista", "o dandismo", constituíam outras estéticas da existência opostas às técnicas de si que eram características da cultura burguesa”.(FOUCAULT, 1994, vol. IV, pág. 629)

A estética de si representa a antítese do individualismo burguês obcecado pela segurança, defesa da propriedade, previdência social, vida confortável dos membros da família; na verdade, a estética da existência é uma moral compartilhada por toda uma comunidade desvinculada da moral do "interesse" existente na sociedade burguesa. A estética da existência, considerada deste ponto de vista, implica em valores e formas de vida criativos, solidários, generosos e ousados, nos limites possíveis da experimentação histórica.

Foucault acrescenta: "eu evoquei, há pouco, a vida "artista", que teve uma importância tão grande no século XIX. Poder-se-ia também considerar a Revolução, não apenas como um projeto político, mas como um estilo, um modo de existência com sua estética própria, seu ascetismo, formas particulares de relação consigo mesmo e com os outros".(FOUCAULT, 1994, vol. IV, pág. 629). A estética da existência pode e deve ser compreendida, como um dos modos possíveis de realização estilística da liberdade, podendo ter até mesmo caráter revolucionário, no melhor sentido kantiano. É a noção de política e de universo político que se transforma, e cabe aos indivíduos e aos grupos sociais a invenção de novas formas de atuação política. As experiências política dos anos sessenta e setenta, quando proliferaram movimentos políticos não programáticos 
como os das prisões, ecológicos, em defesa da liberdade sexual, etc, são marcantes pelo seu enorme poder de contaminação, pelo poder de modificação do comportamento e do pensamento das pessoas.

Os novos movimentos libertários, na medida em que estão voltados para a vida cotidiana, para a experimentação e criação, realizam a atitude de modernidade, que poderia ser resumida assim: "[...] um modo de relação com a atualidade; uma escolha voluntária feita por alguns; enfim, uma maneira de pensar e de sentir, uma maneira também de agir e de se conduzir que, ao mesmo tempo, caracteriza um pertencimento e se apresenta como uma tarefa".(FOUCAULT, 1994, vol. IV, pág. 568)

A atitude de modernidade se mostra particularmente importante num mundo no qual controle e liberdade estão numa tensão agonística incessante, exigindo, portanto, respostas-limite ou atitudes-limite, incompletas e abertas ao porvir. O caráter fugaz da atitude de modernidade tem como exemplo Charles Baudelaire, que em razão de sua vida, por sua obra, e também devido a seu modo de enxergar as coisas. Baudelaire é percebido como um sujeito ético que pôde dar um estilo ou forma à sua vida, como alertou Nietzsche, "ao preço de uma lenta preparação e de um trabalho cotidiano"4, em conformidade com os desafios de seu tempo.

Os motivos para esta homenagem a Baudelaire são os seguintes, em poucas palavras: a) existe em Baudelaire uma postura que supera a aceitação da modernidade como se ela fosse tão somente uma ruptura com a tradição, e, conseqüentemente, consistisse no acatamento das tendências e gostos de um certo tempo; na verdade, há uma distância real entre uma e outra: a atitude de modernidade busca apreender algo de durável no tempo, enquanto que a moda é tão somente uma forma de seguir tendências momentâneas; $b$ ) a atitude de modernidade, por outro lado, não visa a uma sacralização e perpetuação do presente. A atenção com o presente não se resume ao ato de colecionar fatos pitorescos e interessantes apreendidos por uma curiosidade sem critério. O homem da modernidade difere do homem mundano e curioso porque sua atenção pelo presente está a serviço de uma imaginação ativa que não visa a aniquilar a realidade, mas a captá-la no que ela é, sob uma forma irônica e não-conformada. O que entra em cena, neste particular, é o trabalho de transfiguração do real através da articulação da verdade do real com o exercício da liberdade. Assim, "a modernidade baudelairiana é um exercício no qual a extrema atenção com o real é confrontada com a prática de uma liberdade que, ao mesmo tempo, respeita o real e o viola"(Foucault, 1994, vol IV, pág. 570); c) segundo o poeta francês, a modernidade não acontece tão somente como uma forma de se relacionar com as coisas e com o mundo; ela é, sobretudo, um modo especial de relacionamento do indivíduo consigo mesmo, o que exige que se faça um ascetismo e um complexo modo de elaboração de si, sob a modalidade da doutrina da elegância de Baudelaire, que culmina no dandismo, com suas severas regras estéticas. Segundo Baudelaire, o homem moderno não é aquele em sai em busca de suas verdades intrínsecas e de seu ser próprio, mas é aquele que se constitui e se inventa jogando com o seu tempo e com sua subjetividade; d) o lugar de realização da modernidade não se dá na conformidade com as regras morais e com os códigos políticos; seu locus é a invenção, a elaboração de outro(s) modo(s) de vida, dentre os quais os que ligam a arte com a existência.

Aprendemos, com o exemplo de Baudelaire ou Rimbaud, que a redução do problema da arte à política é um dos temas mais empobrecedores da discussão e do fazer estéticos. As formas instituídas e oficiais de ação política, em especial aquelas decorrentes da política partidária, ensinaram que a arte não pode depender da política. A vida política do século XX, com suas repercussões no campo da arte revelou-se verdadeiramente estéril no processo de transformação do enorme campo de tensão em jogo no mundo contemporâneo: fazer depender a arte de posicionamentos políticos, consiste numa abdicação da liberdade e da autonomia da arte e do pensamento. Toda manifestação estética vinda de alguma corrente política, pouco importa sua vertente, sempre resultou em expressões artísticas muito medíocres. Que a atividade artística resulte na renovação tanto do campo perceptivo quanto do mundo vital, eis um fato inegável. 
A vida é o lugar da frágil e fugaz experiência humana. Mudar a si e ao mundo, na experiência da arte, resulta da crença de que é possível o porvir e a invenção de novas formas de vida. Quem se inventa desenha o momento futuro e vai construindo seu próprio espaço de humanidade. A vida é o ponto de partida e o objetivo da arte humana. Como diz a poeta Liane dos Santos, falando do percurso da vida, 'O ouro está na travessia'.

Situar a própria vida como foco de resistência à sociedade de controle, recusar-se a ter uma vida inexpressiva e sem sentido, é criar uma vida outra, inventar novas sensibilidades, tornar-se sempre um artífice de experimentações que resultam numa vida plena de liberdade.

\section{NOTAS}

1. No A Hermenêutica do sujeito, Foucault lembra que a filosofia, a partir do século XIX, retorna à questão do cuidado de si como modo de praticar a filosofia na qual o sujeito é parte inerente ao próprio processo de constituição da ética. Entre o Renascimento, período no qual a estética da existência foi objeto de preocupação efetiva de certos grupos, e o século XVI( ou a Idade Clássica), houve uma ruptura de tal ordem que a subjetividade deixa de ser questão, pois na Idade Clássica existe apenas o sujeito do conhecimento , que tem por finalidade a verdade e a ciência. $\mathrm{O}$ sujeito, como pessoa a se perguntar sobre si mesma, passa séculos sem ser objeto de inquietação e interrogação, deixando de ser elidido como o foi no cartesianismo apenas há dois séculos. Mas agora somos mais produtores e consumidores do que sujeitos. Ver a aula de 6 de janeiro de 1982 deste livro.

2. Prefiro a tradução 'assujeitamento', ao invés de’ sujeitamento', por estar mais de acordo com o pensamento agonístico de Foucault. A assujeitamento consiste num exercício deliberado de controle da subjetividade que constitui a própria individualidade, procurando produzir uma subjetividade voltada para ela mesma e isolada dos outros( como se isto fosse possível).

3. Podemos aprender seu significado pelo pensamento e pelo exemplo de luta como o de Ana Mae Barbosa, importante arte-educadora brasileira.

4. Vide Gaia Ciência, aforismo 290.

\section{REFERÊNCIAS}

BARBOSA, A. M. 1995. Teoria e prática da Educação Artística. SP: Cultrix.

CASTELO BRANCO, G. 2004. A prisão interior in Kafka, Foucault: sem medos (org. Edson Passsetti). SP: Ateliê Editorial.

.2005. O intolerável, in A tolerância e o intempestivo (org. Edson Passetti e Salete Oliveira. SP: Ateliê Editorial.

FOUCAULT, M. 1994. Dits et écrits. Paris: Gallimard, 4 vols.

.2001. L’herméneutique du sujet. Paris: Seuil/Gallimard

NIETZSCHE, F. 1989. Le gai savoir. Paris: Gallimard.

SANTOS, L. 2015. A florista volta ao Éden. RJ: Ibis Libris. 